\title{
Pengaruh Persepsi, Motivasi, Minat, dan Pengetahuan Perpajakan Terhadap Keputusan Mahasiswa Memilih Berkarir DiBidang Perpajakan
}

\author{
Nella Sersa Naradiasari ${ }^{1}$, Djoko Wahyudi ${ }^{2}$ \\ Universitas Stikubank Semarang, Indonesia \\ nellasersa09@gmail.com, djokowahjudi7@gmail.com,
}

\begin{abstract}
*Corresponding Author
Diajukan : 25 Desember 2021

Disetujui : 30 Desember 2021

Dipublikasi : : 1 Januari 2022
\end{abstract}

\section{ABSTRACT}

The choice of a career in taxation is a high desire based in oneself to develop special thoughts, feelings, and actions regarding a career in taxation. This is by directing themselves to a new stage in their lives, seeing their position in life making career decisions. This study aims to examine and analyze the effect of perceptions, motivations, interests, and knowledge of taxation on students' decisions to choose a career in taxation. The population used was students of accounting and management study programs at Stikubank University Semarang and Dian Nuswantoro University Semarang. The sample of this study used a purposive sampling method with the criteria of Accounting and Management students who had taken taxation courses and obtained a sample of 100 respondents. In this study, primary data is used, namely data that is collected and processed by yourself, the results are in the form of numbers listed on a questionnaire scale which are processed using SPSS. The technique used in data collection is a questionnaire questionnaire media. The data analysis technique used is multiple linear regression analysis. The results of this study indicate that perceptions and motivations have a positive effect on student decisions to choose a career in taxation. Likewise, the variables of interest and knowledge of taxation also have a positive influence on students' decisions to choose a career in taxation.

Keywords: Interests; Motivation; Tax Knowledge; Perception

\section{PENDAHULUAN}

Pendidikan merupakan suatu perwujudan seni dan budaya manusia yang dinamis dan syarat akan perkembangan. Gagasan ini mengandung konsekuensi bahwa peningkatan dan atau penguatan pelatihan vokasi untuk mengantisipasi kebutuhan dan tantangan dimasa depan harus terus menerus selaras dengan kebutuhan perkembangan, ilmu pengetahuan, pengetahuan, teknologi, seni dan budaya. Perwujudan tersebut bisa dilihat dari adanya persepsi mahasiswa dalam memilih profesi di bidang perpajakan tentu akan berdampak pada karir itu sendiri.

Profesi dibidang perpajakan sangat dibutuhkan agar operasional perpajakan di Indonesia dapat berjalan dengan baik. Di Indonesia karir dibidang perpajakan cenderung sedikit peminatnya. Kurangnya minat untuk berkarir dibidang perpajakan biasanya disebabkan oleh kurangnya pengetahuan mahasiswa tentang perpajakan serta peluang kerja dibidang perpajakan. Saat ini jumlah pegawai pajak yang ada di seluruh Indonesia adalah 32.214 orang, hal ini tentunya sangat tidak seimbang dengan jumlah wajib pajak yang berjumlah 30.044.103 orang (pajak.go.id).

Penelitian ini dilakukan, karena masih terjadi fenomena, research gap, dan perbedaan objek yang digunakan peneliti. Peneliti menggunakan objek mahasiswa program studi akuntansi serta manajemen pada Universitas Stikubank Semarang dan Universitas Dian Nuswantoro Semarang. Sedangkan peneliti sebelumnya menggunakan objek mahasiswa akuntansi program S1 pada Universitas Pendidikan Ganesha.

Persepsi adalah pengorganisasian, penginterptrestasian terhadap stimulus pada inderannya dan merupakan respon yang integrated dalam diri seseorang. Peneliti-peneliti sebelumnya Mahayani, dkk 
Owner: Riset \& Jurnal Akuntansi

e-ISSN : 2548-9224 | p-ISSN : 2548-7507

Volume 6 Nomor 1, Januari 2022

DOI : https://doi.org/10.33395/owner.v6i1.622

(2017); Rachmawati, dkk (2017); Pradnyani, dkk (2018); Yasa, dkk (2019); Anggraeni, dkk (2020) mengungkapkan hasil penelitian bahwa persepsi berpengaruh positif terhadap keputusan pemilihan berkarir dibidang perpajakan. Namun berbeda dengan hasil penelitian yang dilakukan oleh Samsuri, dkk (2016) yang menyatakan persepsi tidak berpengaruh terhadap keputusan pemilihan berkarir di bidang perpajakan.

Motivasi adalah dorongan untuk melakukan suatu tindakan mencapai suatu tujuan tertentu. Motivasi menjadi suatu keadaan yang kompleks dan memotivasi seseorang baik secara sadar dan tidak sadar untuk bergerak menuju tujuan tertentu. Berdasarkan hasil penelitian yang dilakukan oleh Mahayani, dkk (2017); Rachmawati, dkk (2017); Meilani (2020); Anggraeni, dkk (2020); Prihatin, dkk (2020); Nareswari, dkk (2021) menyatakan bahwa motivasi berpengaruh positif terhadap keputusan pilihan berkarir di bidang perpajakan. Namun berbeda dengan hasil penelitian dari Setya (2017) yang menyatakan bahwa motivasi tidak berpengaruh terhadap keputusan pemilihan berkarir di bidang perpajakan.

Minat merupakan kecenderungan yang agak menetap pada subjek untuk merasa tertarik pada bidang tertentu dan merasa senang berkecimpung dalam bidang tersebut. Menurut Rahmalia (2015) Minat diartikan sebagai dorongan perhatian untuk sesuatu yang melibatkan perasaan dan pikiran seseorang. Penelitian terdahulu yang dilakukan oleh Mahayani, dkk (2017) menyatakan bahwa minat berpengaruh positif terhadap keputusan pemilihan berkarir di bidang perpajakan.

Pengetahuan perpajakan merupakan usaha yang mendewasakan seseorang melewati pengajaran atau pelatihan dengan cara mengubah perilaku wajib pajak atau sekelompok wajib pajak melalui pengajaran dan pelatihan. Wajib pajak akan secara sukarela mematuhi, apabila mereka memahami konsep dasar perpajakan. Hasil penelitian yang dilakukan oleh Mahayani, dkk (2017); Meilani (2020); Nareswari, dkk (2021) menyatakan bahwa pengetahuan perpajakan bepengaruh postif dan signifikan terhadap keputusan pemilihan berkarir di bidang perpajakan.

\section{Persepsi}

\section{STUDI LITERATUR}

Persepsi merupakan suatu pandangan, baik positif maupun negatif yang terbentuk dari sikap seseorang terhadap sesuatu. Menurut Theory Of Reasoned Action (TRA) dalam kehidupan sehari-hari persepsi mahasiswa cenderung terpengaruh dari orang sekitar. Biasanya keluarga, lingkungan pergaulan dan dosen menciptakan persepsi mahasiswa. Apabila mahasiswa memiliki pemikiran atau persepsi tentang karir di bidang perpajakan maka mahasiswa tersebut akan berperilaku sesuai dengan apa yang diharapkan. Berdasarkan persepsi yang baik tentunya akan memunculkan tingginya minat mahasiswa berkarir dibidang perpajakan. Pernyataan tersebut sejalan dengan hasil penelitian yang dilakukan oleh Mahayani, dkk (2017).

\section{H1 : Persepsi berpengaruh positif terhadap keputusan mahasiswa memilih berkarir di bidang perpajakan.}

\section{Motivasi}

Motivasi adalah bagian dari norma subjektif yang dapat mempengaruhi perilaku seseorang. Dalam Theory of Reasoned Action (TRA) ketika mahasiswa memperoleh mata kuliah perpajakan cenderung termotivasi oleh ilmu yang diajarkan dosen tersebut. Mahasiswa yang menguasai ilmu perpajakan memiliki daya tarik untuk terjun berkarir dibidang perpajakan. Hal ini juga berpengaruh kepada orang lain, sehingga apabila motivasi sosial mahasiswa itu baik dengan karir dibidang perpajakan maka akan berpengaruh terhadap minat mahasiswa untuk berkarir di bidang perpajakan juga tinggi. Pernyataan ini sejalan dengan hasil penelitian terdahulu yang dilakukan oleh Mahayani, dkk (2017).

\section{H2 : Motivasi berpengaruh positif terhadap keputusan mahasiswa memilih berkarir di bidang perpajakan}

\section{Minat}

Minat dapat dikatakan sebagai faktor motivasi seseorang yang mempengaruhi perilaku, mengidentifikasikan bagaimana kerasnya seseorang berusaha, seberapa besar usaha mereka 
Owner: Riset \& Jurnal Akuntansi

e-ISSN : 2548-9224 | p-ISSN : 2548-7507

Volume 6 Nomor 1, Januari 2022

DOI : https://doi.org/10.33395/owner.v6i1.622

merencanakan penekanan, untuk membentuk suatu perilaku. Dalam pendekatan Theory of Planned Behavior (TPB), jika mahasiswa memiliki minat atau keinginan tertentu maka secara tidak langsung akan mempengaruhi usaha yang akan dilakukan untuk mencapai tujuannya tersebut dalam berkarir di bidang perpajakan. Jadi dapat dikatakan bahwa ketika seorang mahasiswa memiliki minat atau keinginan untuk berkarir di bidang perpajakan maka mahasiswa tersebut akan berusaha untuk mencapai harapannya. Pernyataan ini sejalan dengan penelitian yang dilakukan oleh Mahayani, dkk (2017).

H3 : Minat berpengaruh positif terhadap keputusan mahasiswa memilih berkarir di bidang perpajakan

\section{Pengetahuan Perpajakan}

Pengetahuan Perpajakan merupakan kemauan untuk belajar melalui pendidikan formal maupun non formal mengenai tata cara dan ketentuan perpajakan maka, seseorang tersebut akan meningkatkan pengetahuannya mengenai perpajakan. Dakam Theory of Planned Behavior (TPB) tingkatan pendidikan yang dilalui oleh mahasiswa maka ilmu yang didapat akan semakin meningkat pula. Pengetahuan yang dimaksud adalah pengetahuan mengenai sistem perpajakan, cara-cara menghitung pajak. Dengan demikian, mendorong mahasiswa memiliki suatu gambaran mengenai hal-hal yang akan ia kerjakan, apabila bekerja dibidang perpajakan. Penelitian ini sejalan dengan hasil penelitian terdahulu Hawani dan Mahayani, dkk (2017).

\section{H4 : Pengetahuan perpajakan berpengaruh positif terhadap keputusan mahasiswa memilih berkarir di bidang perpajakan}

\section{METODE}

Jenis penelitian yang digunakan dalam penelitian ini adalah penelitian kuantitatif dengan data primer. Teknik yang digunakan dalam pengambilan data adalah dengan media angket kuesioner. Populasi pada penelitian ini adalah mahasiswa program studi akuntansi dan manajemen di Universitas Stikubank Semarang dan Universitas Dian Nuswantoro Semarang. Penentuan sampel menggunakan metode purposive sampling dengan kriteria mahasiswa program studi Akuntansi dan Manajemen pada Universitas Stikubank Semarang dan Universitas Dian Nuswantoro Semarang yang sudah menempuh mata kuliah perpajakan, sehingga diperoleh sampel sebanyak 100 responden.

\section{Definisi Operasional Variabel}

\section{Pemilihan Berkarir Di Bidang Perpajakan}

Variabel berkarir di bidang perpajakan diukur dengan instrumen pernyataan dari Mahayani (2017), meliputi indikator-indikator sebagai berikut: (1) Untuk mendapatakan promosi jabatan; (2) Perkembangan profesi di bidang perpajakan; (3) Mendapat gelar konsultan; (4) Mendapatkan penilaian baik atas kinerja; (5) Meningkatkan karir di bidang perpajakan.

\section{Persepsi}

Variabel persepsi diukur dengan instrumen pernyataan dari Trisnawati dan Rusydi (2015: 9), meliputi indikator-indikator sebagai berikut: (1) Proses perkuliahan pajak akan membantu ketika berkarir dibidang perpajakan; (2) Pengetahuan tentang pajak akan sangat bermanfaat dalam karir di bidang perpajakan; (3) Pelatihan sebelum berkarir di bidang perpajakan membantu dalam pengembangan karir; (4) Karir di bidang perpajakan akan dapat meningkatkan kemampuan analitis, decisionmaking, dan problem sloving untuk memecahkan masalah pajak; (5) Karir di bidang perpajakan akan menambah kemampuan interpersonal seperti kemampuan bekerja sama dalam kelompok.

\section{Motivasi}

Variabel motivasi diukur dengan instrumen pernyataan dari Trisnawati dan Rusydi (2015: 9), meliputi indikator-indikator sebagai berikut: (1) Menginginkan pekerjaan di bidang perpajakan, karena sesuai dengan pendidikan di jurusan akuntansi; (2) Meningkatkan keahlian dalam mengaplikasikan pengetahuan perpajakan untuk memecahkan masalah-masalah riil dalam kehidupan 
Owner: Riset \& Jurnal Akuntansi

e-ISSN : 2548-9224 | p-ISSN : 2548-7507

Volume 6 Nomor 1, Januari 2022

DOI : https://doi.org/10.33395/owner.v6i1.622

sehari-hari; (3) Meningkatkan kemampuan berprestasi ketika berkarir di bidang perpajakan; (4) Mendapatkan pekerjaan yang memberikan gaji tambahan (diluar gaji pokok, seperti honor) yang tinggi; (5) Mendapatkan pengetahuan berkaitan dengan peran dan tanggung jawan yang akan dimiliki ketika berada di tengah-tengah masyarakat.

\section{Minat}

Variabel minat diukur dengan instrumen pernyataan dari Trisnawati dan Rusydi (2015:9), meliputi indikator-indikator adalah sebagai berikut: (1) karir di bidang perpajakan memberikan peluang yang besar bagi mahasiswa akuntansi; (2) Tertarik berkarir di bidang perpajakan, karena memberikan pengalaman dan pengetahuan tentang pajak; (3) Berminat berkarir di bidang perpajakan, karena memberikan gaji yang besar; (4) Berminat berkarir di bidang perpajakan, karena akan mendapat fasilitas yang memadai; (5) Akan berkarir di bidang perpajakan setelah studi selesai.

\section{Pengetahuan Perpajakan}

Variabel pengetahuan perpajakan diukur dengan instrumen pernyataan dari Mahayani (2017), meliputi indikator-indikator sebagai berikut: (1) Menambah pengetahuan dalam perpajakan; (2) Pengetahuan mengenai ketentuan umum perpajakan; (3) Meningkatkan pengetahuan peraturan perpajakan; (4) Dapat meningkatkan mengenai isu-isu peraturan perpajakan; (5) Dapat meningkatkan pengetahuan dan pengaruh terhadap keputusan keuangan.

\section{Teknik Analisis Data}

\section{Analisis Statistik Deskriptif}

Analisis statistik deskriptif adalah teknik deskriptif yang memberikan gambaran suatu data sehingga menjadikan sebuah informasi yang lebih jelas dan mudah untuk dipahami, hal ini dilihat dari nilai jumlah sampel, rata-rata (mean), standard deviasi, nilai maksimum, dan nilai minimum (Ghozali, 2016).

\section{Uji Kualitas Data \\ Uji Validitas}

Uji validitasi bertujuan membandingkan nilai $r$ hitung dengan $r$ tabel untuk degree of freedom $(\mathrm{df})=\mathrm{n}-2$, dimana $\mathrm{n}$ merupakan jumlah sampel. $\mathrm{R}$ tabel akan di peroleh dari tabel product moment (Ghozali,2006).

\section{Uji Reliabilitas}

Teknik statistik yang digunakan untuk pengujian tersebut dengan koefisien cronb ach's alpha setelah dilakukan pengukuran dengan mengguankan software SPSS. Cronbach's Alpha merupakan uji reliabilitas untuk alternatif jawaban lebih dari dua. Secara umum suatu instrumen dikatakan bagus jika memiliki koefisien cronbach's alpha > 0,6 (Supramono dan Utami, 2004).

\section{Uji Normalitas}

Pengujian normalitas data akan digunakan alat uji Kolmogorov Smirnov. Distribusi data akan dikatakan normal apabila nilai asymp.sig 2-tailed > 0.05 (Ghozali, 2013).

\section{Uji Asumsi Klasik \\ Uji Multikolineraritas}

Pengujian Multikolineraritas dilakukan menggunakan Variance Inflation Factor (VIP) dan Tolerance. Multikolineraritas terjadi jika VIF lebih besar dari 10 dan nilai Tolerance kurang dari 0,1 atau jika antar variabel independen ada korelasi yang cukup tingginya umumnya diatas 0,9 (Ghozali, 2005).

\section{Uji Heteroskedastisitas}


Owner: Riset \& Jurnal Akuntansi

e-ISSN : 2548-9224 | p-ISSN : 2548-7507

Volume 6 Nomor 1, Januari 2022

DOI : https://doi.org/10.33395/owner.v6i1.622

Salah satu cara mendeteksi heteroskedastisitas ini dengan melihat pola sebaran pada grafik scatter plot. Jika ada pola tertentu misalnya titik-titik yang membentuk pola tertentu yang teratur maka mengindiksikan bahwa terjadi heteroskedastisitas dan jika tidak ada pola yang jelas serta titik-titik menyebar di atas dan di bawah angka 0 pada sumbu Y maka tidak terjadi heteroskedastisitas (Ghozali, 2005).

\section{Analisis Regresi Linier Berganda}

Analisis regresi berganda memiliki tujuan untuk menunjukksn orientasi hubungan variabel dependen dan independen (Ghozali, 2018: 96). Berikut persamaan regresi yang digunakan untuk menguji hipotesis penelitian ini :

Keterangan :

$$
\mathrm{Y}=\beta_{1} \mathrm{X}_{1}+\beta_{2} \mathrm{X}_{2}+\beta_{3} \mathrm{X}_{3}+\beta_{4} \mathrm{X}_{4}+\mathrm{e}
$$

$$
\begin{array}{llll}
\mathrm{Y} & =\begin{array}{l}
\text { Keputusan Pemilihan Berkarir Di } \\
\text { Bidang Perpajakan }
\end{array} & \mathrm{X} 2 & =\text { Motivasi } \\
\beta & =\text { K3 } & =\text { Minat } \\
\mathrm{X} 1 & =\text { Peefesien Regresi Linier } & \mathrm{X} 4 & =\text { Pengetahuan Perpajakan } \\
& \mathrm{e} & =\text { error term (residual) }
\end{array}
$$

\section{Uji Model}

Uji F

Signifikansi yang digunakan untuk melakukan pengujian pada hipotesis ini adalah sebesar 5\% atau 0,05 . Hipotesis dinyatakan diterima, apabila nilai probabilitas signifikan $<0,05$, dapat diartikan bahwa model regresi tersebut dapat digunakan untuk memprediksi variabel independen. Hipotesis dinyatakan ditolak, apabila nilai probabilitas 60 signifikan > 0,05, dapat diartikan bahwa model regresi tersebut tidak dapat digunakan untuk memprediksi variabel dependen (Ghozali, 2013).

\section{Koefesien Determinasi $\left(\mathbf{R}^{2}\right)$}

Uji koefisien determinasi menguji goodness of fit model regresi. Nilai koefisien determinasi adalah 0 dan 1 . Jika nilai $\mathrm{R}^{2}$ kecil maka kemampuan variabel bebas dalam menjelaskan variabel terkait dapat dikatakan sangat terbatas apabila nilai $\mathrm{R}^{2}$ kecil.

\section{Uji Statistik t}

Uji statistik t pada dasarnya menunjukkan seberapa jauh pengaruh satu variabel penjelas atau independen secara individual dalam menerangkan variasi variabel dependen, Uji t, uji signifikan apakah variabel independen secara parsial berpengaruh signifikan terhadap variabel dependen (Ghozali, 2006). Hal ini dilakukan dengan cara membandingkan P-value lebih kecil dari 0,05 maka $\mathrm{H} 1, \mathrm{H} 2, \mathrm{H} 3, \mathrm{H} 4$ diterima dan sebaliknya, hipotesis akan diuji dengan menggunakan tingkat signifikansi sebesar $5 \%$ atau 0,05 .

\section{Gambaran Umum Responden}

\section{HASIL}

Tabel 1. Responden Berdasarkan Jenis Kelamin

\begin{tabular}{llcc}
\hline No & Jenis Kelamin & Jumlah Responden & Persen (\%) \\
\hline 1 & Perempuan & 83 & $83 \%$ \\
2 & Laki-Laki & 17 & $17 \%$ \\
Jumlah & $\mathbf{1 0 0}$ & $\mathbf{1 0 0 \%}$ \\
\hline
\end{tabular}

Sumber: Data Primer diolah, 2021

Berdasarkan tabel 1 di atas menunjukkan bahwa dari 100 responden mahasiswa laki-laki berjumlah 17 orang atau $17 \%$ dan mahasiswa perempuan sebanyak 83 orang atau $83 \%$. Hal ini menunjukkan bahwa sebagian besar yang memilih berkarir dibidang perpajakan adalah perempuan.

Tabel 2. Responden Berdasarkan Jurusan

\begin{tabular}{lllc}
\hline No & Jurusan & Jumlah Responden & Persen (\%) \\
\hline 1. & Akuntansi & 30 & $30 \%$ \\
2. & Manajemen & 70 & $70 \%$
\end{tabular}


Owner: Riset \& Jurnal Akuntansi

e-ISSN : 2548-9224 | p-ISSN : 2548-7507

Volume 6 Nomor 1, Januari 2022

DOI : https://doi.org/10.33395/owner.v6i1.622

Jumlah $\quad 100 \quad 100 \%$

Sumber: Data Primer diolah, 2021

Berdasarkan tabel 2 menunjukkan bahwa dari 100 responden mahasiswa jurusan manajemen berjumlah 30 orang atau $30 \%$ dan mahasiswa jurusan akuntansi sebanyak 70 orang atau $70 \%$. Hal ini menunjukkan bahwa sebagian besar yang memilih berkarir dibidang perpajakan adalah mahasiswa dari jurusan akuntansi.

\begin{tabular}{lccc}
\multicolumn{4}{c}{ Tabel 3. Responden Berdasarkan Semester } \\
\hline No & Semester & $\begin{array}{l}\text { Jumlah } \\
\text { (Responden) }\end{array}$ & $\begin{array}{c}\text { Persen } \\
(\%)\end{array}$ \\
\hline 1. & 1 & 1 & $1 \%$ \\
2. & 3 & 3 & $3 \%$ \\
3. & 4 & 1 & $1 \%$ \\
4. & 5 & 32 & $32 \%$ \\
5. & 6 & 7 & $7 \%$ \\
6. & 7 & 53 & $53 \%$ \\
7. & 8 & 3 & $3 \%$ \\
Jumlah & & $\mathbf{1 0 0}$ & $\mathbf{1 0 0 \%}$ \\
\hline
\end{tabular}

Sumber: Data Primer diolah, 2021

Berdasarkan tabel 3 di atas menunjukkan bahwa dari 100 responden mahasiswa semester 1 berjumlah 1 orang atau $1 \%$ dan mahasiswa semester 3 sebanyak 3 orang atau 3\%, semester 4 berjumlah 1 orang atau $1 \%$, semester 5 berjumlah 32 orang atau 32\%, semester 6 berjumlah 7 orang atau $7 \%$, semester 7 berjumlah 53 orang atau 53\%, Sedangkan semester 8 berjumlah 3 orang atau 3\% Hal ini menunjukkan bahwa sebagian besar yang memilih berkarir dibidang perpajakan adalah mahasiswa semester 7 sebesar 53 orang atau $53 \%$.

Tabel 4. Responden Berdasar Asal Universitas

\begin{tabular}{llcc}
\hline No & Asal Universitas & Jumlah (Responden) & Persen (\%) \\
\hline 1. & UNISBANK & 54 & $54 \%$ \\
2. & UDINUS & 46 & $46 \%$ \\
Jumlah & $\mathbf{1 0 0}$ & $\mathbf{1 0 0 \%}$ \\
\hline
\end{tabular}

Sumber: Data Primer diolah, 2021

Berdasarkan tabel 4. di atas menunjukkan bahwa dari 100 responden mahasiswa dari universitas UNISBANK berjumlah 54 orang atau 54\% dan mahasiswa dari Universitas UDINUS sebanyak 46 orang atau 46\%. Hal ini menunjukkan bahwa sebagian besar yang memilih berkarir dubidang perpajakan adalah mahasiswa yang berasal dari universitas UNISBANK sebanyak 54 orang atau 54\%.

Teknik Analisis Data

Analisis Statistik Deskriptif

Tabel 5. Hasil Uji Statistik Deskriptif

Descriptive Statistics

\begin{tabular}{lrrrrr}
\hline & N & Minimum & Maximum & Mean & Std. Deviation \\
\hline Persepsi & 100 & 9.00 & 25.00 & 18.8400 & 3.28363 \\
Motivasi & 100 & 10.00 & 25.00 & 19.2700 & 4.00216 \\
Minat & 100 & 11.00 & 25.00 & 18.5400 & 3.40653 \\
Pengetahuan & 100 & 13.00 & 24.00 & 19.2800 & 3.17846 \\
Keputusan Pemilihan & 100 & 13.00 & 24.00 & 19.3200 & 3.13623 \\
Valid N (listwise) & 100 & & & & \\
\hline
\end{tabular}

Sumber: Output SPSS 2021

Berdasarkan tabel 5 menunjukan bahwa variabel persepsi terhadap keputusan mahasiswa memilih berkarir di bidang perpajakan memiliki nilai minimum sebesar 9 dan nilai maksimum sebesar 25. Rata-rata variabel persepsi terhadap keputusan mahasiswa memilih berkarir di bidang perpajakan 
Owner: Riset \& Jurnal Akuntansi

e-ISSN : 2548-9224 | p-ISSN : 2548-7507

Volume 6 Nomor 1, Januari 2022

DOI : https://doi.org/10.33395/owner.v6i1.622

sebesar 18.8400, sedangkan standar devinasi sebesar 3.28363. nilai rata-rata lebih besar dari standar deviasi, artinya data terdistribusi dengan baik.

Variabel motivasi terhadap keputusan mahasiswa memilih berkarir di bidang perpajakan memiliki nilai minimum sebesar 10 dan nilai maksimum sebesar 25 . Rata-rata variabel persepsi terhadap keputusan mahasiswa memilih berkarir di bidang perpajakan sebesar 19.2700, sedangkan standar devinasi sebesar 4.00216. nilai rata-rata lebih besar dari standar deviasi, artinya data terdistribusi dengan baik.

Variabel minat terhadap keputusan mahasiswa memilih berkarir di bidang perpajakan memiliki nilai minimum sebesar 11 dan nilai maksimum sebesar 25. Rata-rata variabel persepsi terhadap keputusan mahasiswa memilih berkarir di bidang perpajakan sebesar 18.5400, sedangkan standar devinasi sebesar 3.40653. nilai rata-rata lebih besar dari standar deviasi, artinya data terdistribusi dengan baik.

Variabel pengetahuan perpajakan terhadap keputusan mahasiswa memilih berkarir di bidang perpajakan memiliki nilai minimum sebesar 13 dan nilai maksimum sebesar 24 . Rata-rata variabel persepsi terhadap keputusan mahasiswa memilih berkarir di bidang perpajakan sebesar 19.2800, sedangkan standar devinasi sebesar 3.17846. nilai rata-rata lebih besar dari standar deviasi, artinya data terdistribusi dengan baik.

Variabel keputusan pemilihan berkarir memiliki nilai minimum sebesar 13 dan nilai maksimum sebesar 24. Rata-rata variabel persepsi terhadap keputusan mahasiswa memilih berkarir di bidang perpajakan sebesar 19.3200, sedangkan standar devinasi sebesar 3.13623. nilai rata-rata lebih besar dari standar deviasi, artinya data terdistribusi dengan baik.

\section{Uji Kualitas Data}

\section{Uji Validitas}

Tabel 6. Hasil Uji Validitas

\begin{tabular}{|c|c|c|c|c|c|}
\hline No & Variabel & Indikator & $r_{\text {htuung }}$ & $\mathrm{r}_{\text {tabel }}$ & Keterangan \\
\hline \multirow[t]{5}{*}{1.} & Persepsi $\left(\mathrm{X}_{1}\right)$ & $\mathrm{X}_{1 \cdot 1}$ & 0,846 & 0,196 & valid \\
\hline & & $X_{1 \cdot 2}$ & 0,829 & 0,196 & valid \\
\hline & & $X_{1 \cdot 3}$ & 0,822 & 0,196 & valid \\
\hline & & $X_{1 \cdot 4}$ & 0,827 & 0,196 & valid \\
\hline & & $X_{1 \cdot 5}$ & 0,796 & 0,196 & valid \\
\hline \multirow[t]{5}{*}{2.} & Motivasi $\left(\mathrm{X}_{2}\right)$ & $X_{2 \cdot 1}$ & 0,832 & 0,196 & valid \\
\hline & & $\mathrm{X}_{2 \cdot 2}$ & 0,920 & 0,196 & valid \\
\hline & & $X_{2 \cdot 3}$ & 0,851 & 0,196 & valid \\
\hline & & $X_{2 \cdot 4}$ & 0,920 & 0,196 & valid \\
\hline & & $X_{2 \cdot 5}$ & 0,581 & 0,196 & valid \\
\hline \multirow[t]{5}{*}{3.} & Minat $\left(\mathrm{X}_{3}\right)$ & $X_{3 \cdot 1}$ & 0,815 & 0,196 & valid \\
\hline & & $X_{3 \cdot 2}$ & 0,894 & 0,196 & valid \\
\hline & & $X_{3 \cdot 3}$ & 0,915 & 0,196 & valid \\
\hline & & $X_{3 \cdot 4}$ & 0,619 & 0,196 & valid \\
\hline & & $X_{3 \cdot 5}$ & 0,895 & 0,196 & valid \\
\hline \multirow[t]{5}{*}{4.} & Pengetahuan & $X_{4 \cdot 1}$ & 0,871 & 0,196 & valid \\
\hline & Perpajakan $\left(X_{4}\right)$ & $X_{4 \cdot 2}$ & 0,806 & 0,196 & valid \\
\hline & & $X_{4 \cdot 3}$ & 0,824 & 0,196 & valid \\
\hline & & $X_{4 \cdot 4}$ & 0,680 & 0,196 & valid \\
\hline & & $X_{4 \cdot 5}$ & 0,716 & 0,196 & valid \\
\hline \multirow[t]{5}{*}{5.} & Pemilihan & $\mathrm{Y}_{\cdot 1}$ & 0,857 & 0,196 & valid \\
\hline & Keputusan (Y) & $\mathrm{Y}_{\cdot 2}$ & 0,857 & 0,196 & valid \\
\hline & & $\mathrm{Y}_{\cdot 3}$ & 0,849 & 0,196 & valid \\
\hline & & $\mathrm{Y}_{4}$ & 0,781 & 0,196 & valid \\
\hline & & $\mathrm{Y}_{\cdot 5}$ & 0,641 & 0,196 & valid \\
\hline
\end{tabular}

Sumber: Output SPSS 2021 
Owner: Riset \& Jurnal Akuntansi

e-ISSN : 2548-9224 | p-ISSN : 2548-7507

Volume 6 Nomor 1, Januari 2022

DOI : https://doi.org/10.33395/owner.v6i1.622

Berdasarkan tabel 6 menunjukkan bahwa nilai $\mathrm{r}_{\text {htung }}$ untuk maisng-masing variabel $>$ dari nilai $r$ tabel, sehingga semua item pertanyaan yang digunakan pada masing-masing variabel penelitian ini dinyatakan valid dan data tersebut dapat digunakan sebagai data peneltian.

\section{Uji Reliabilitas}

\begin{tabular}{lccc}
\multicolumn{4}{c}{ Tabel 7. Hasil uji Reliabilitas } \\
\hline \multicolumn{1}{c}{ Variabel } & Cronbach'sAlpha & Standart Reliabilitas & Keterangan \\
\hline Persepsi X1 & 0,879 & 0,60 & Reliabel \\
Motivasi X2 & 0,922 & 0,60 & Reliabel \\
Minat X3 & 0,886 & 0,60 & Reliabel \\
Pengetahuan Perpajakn X4 & 0,841 & 0,60 & Reliabel \\
Keputusan Pemilihan (Y) & 0,852 & 0,60 & Reliabel \\
\hline
\end{tabular}

Sumber: Output SPSS 2021

Berdasarkan tabel 7 hasil uji reliabilitas seluruh variabel dalam penelitian ini dapat dikatakan reliabel dan layak, karena nilai Cronbach Alpha lebih besar dari 0,6. Dengan demikian, dapat disimpulkan bahwa seluruh indikator pengukur variabel dari kuesioner adalah reliabel, yang artinya bahwa kuesioner yang digunakan dalam penelitian ini merupakan kuesioner yang handal.

\section{Uji Normalitas}

Tabel 8. Hasil uji Normalitas

One-Sample Kolmogorov-Smirnov Test

\begin{tabular}{llr}
\hline & & Unstandardized Residual \\
\hline $\mathrm{N}$ & & 100 \\
Normal Parameters & & \\
& Mean &, 0000000 \\
Most Extreme Differences & Std. Deviation & 1,20040484 \\
\cline { 2 - 3 } & Absolute &, 085 \\
& Positive &, 085 \\
Test Statistic & Negative &,- 079 \\
\cline { 2 - 3 } Asymp. Sig. (2-tailed) & &, 085 \\
& &, $069^{\mathrm{c}}$
\end{tabular}

Sumber: Output SPSS 2021

Berdasarkan tabel 8 menunjukan bahwa nilai Asymp. Sig. (2-tailed) sebesar 0,069>0,05 hal ini menunjukan bahwa data terdistribusi secara normal, sehingga sampel tersebut memenuhi syarat untuk pebelitian lebih lanjut.

\section{Uji Asumsi Klasik}

Uji Multikolonieritas

Tabel 9. Hasil Uji Multikolonieritas

Coefficients $^{\mathrm{a}}$

\begin{tabular}{llcr}
\hline \multicolumn{4}{c}{ Coefficients $^{\mathrm{a}}$} \\
\hline \multicolumn{3}{c}{ Collinearity Statistics } \\
\hline \multirow{2}{*}{1} & Tolerance & VIF \\
\cline { 2 - 4 } & (Constant) &, 381 & 2,627 \\
\cline { 2 - 4 } & PERSEPSI (X1) &, 316 & 3,163 \\
& MOTIVASI (X2) &, 546 & 1,833 \\
& MINAT (X3) &, 216 & 4,637 \\
& PENGETAHUAN & & \\
& PERPAJAKAN (X4) & & \\
\hline
\end{tabular}

Sumber: Output SPSS 2021 
Owner: Riset \& Jurnal Akuntansi

e-ISSN : 2548-9224 | p-ISSN : 2548-7507

Volume 6 Nomor 1, Januari 2022

DOI : https://doi.org/10.33395/owner.v6i1.622

Berdasarkan tabel 9 menunjukan bahwa masing-masing variabel memiliki VIF $<10$ dan tolerance $>0,10$ maka dapat disimpulkan data tersebut tidak mengalami gejala multikolineritas atau tidak ada keterkaitan variabel bebas.

\section{Uji Heterokedastisitas}

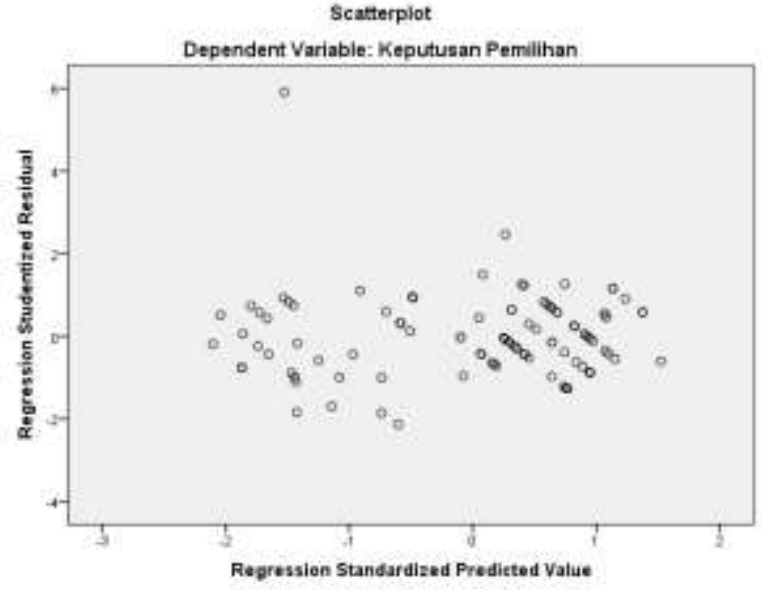

Gambar 1. Hasil Uji Heterokedastisitas

Sumber: Output SPSS 2021

Dari gambar 1 hasil scatterplot diatas terlihat titik-titik yang menyebar secara acak serta tersebar baik diatas maupun dibawah angka 0 dan sumbu Y. Dengan demikian dapat disimpulkan bahwa tidak terjadi heteroskedastisitas pada model regresi, sehingga model regresi layak untuk digunakan dalam melakukan pengujian.

\section{Analisis Regresi Linier Berganda}

Tabel 10. Hasil Uji Regresi Linear Berganda Coefficients $^{\mathrm{a}}$

\begin{tabular}{|c|c|c|c|c|c|c|}
\hline \multirow{2}{*}{\multicolumn{2}{|c|}{ Model }} & \multicolumn{2}{|c|}{$\begin{array}{l}\text { Unstandardized } \\
\text { Coefficients }\end{array}$} & \multirow{2}{*}{$\begin{array}{l}\text { Standardized } \\
\text { Coefficients } \\
\text { Beta }\end{array}$} & \multirow[b]{2}{*}{$\mathrm{t}$} & \multirow[b]{2}{*}{ Sig } \\
\hline & & B & Std. Error & & & \\
\hline \multirow[t]{5}{*}{1} & (Constant) & 1,232 & ,819 & & 1,503 & ,136 \\
\hline & PERSEPSI (X1) &, 175 & 061 & ,183 & 2,875 & 005 \\
\hline & MOTIVASI (X2) & 185 & 055 & ,236 & 3,377 & 001 \\
\hline & MINAT (X3) & , 120 & ,049 & ,130 & 2,442 & ,016 \\
\hline & $\begin{array}{l}\text { PENGETAHUAN } \\
\text { PERPAJAKAN (X4) }\end{array}$ & 468 & ,083 & ,474 & 5,606 & ,000 \\
\hline
\end{tabular}

Sumber: Output SPSS 2021

Berdasarkan tabel 10 dapat disusun persamaan regresi sebagai berikut:

Keputusan minat mahasiswa $=$ 0,183(Persepsi $)+0,236($ Motivasi $)+0,130($ Minat $)+0,474$ (Pengetahuan Perpajakan) + e

\section{Uji Model}

Uji F

Tabel 11. Hasil Uji F ANOVA $^{\mathrm{a}}$

\begin{tabular}{clrrrrr}
\hline Model & & Sum of Squares & \multicolumn{1}{c}{ df } & Mean Square & \multicolumn{1}{c}{ F } & \multicolumn{1}{c}{ Sig. } \\
\hline 1 & Regression & 831,104 & 4 & 207,776 & 138,366 &, $000^{\mathrm{b}}$ \\
& Residual & 142,656 & 95 & 1,502 & & \\
& Total & 973,760 & 99 & & & \\
\hline
\end{tabular}

Sumber: Output SPSS 2021 
Owner: Riset \& Jurnal Akuntansi

e-ISSN : 2548-9224 | p-ISSN : 2548-7507

Volume 6 Nomor 1, Januari 2022

DOI : https://doi.org/10.33395/owner.v6i1.622

Berdasarkan tabel 11 menunjukan bahwa nilai $\mathrm{F}$ sebesar 138,366 dengan nilai signifikansi sebesar $0,000<0,05$. Hal ini berarti model regresi pada penelitian ini dikatakan layak atau fit.

\section{Uji Koefisien Determinasi}

Tabel 12. Hasil uji koefisien determinasi

Model Summary ${ }^{\mathrm{b}}$

\begin{tabular}{lrrrrr}
\hline Model & R & R Square & Adjusted R Square & Std. Error of the Estimate & Durbin-Watson \\
\hline 1 &, $924^{\mathrm{a}}$ &, 853 &, 847 & 1,2254 & 2,121 \\
\hline
\end{tabular}

Sumber: Output SPSS 2021

Erdasarkan tabel 12 menunjukkan bahwa nilai Adjusted $R^{2}$ sebesar 0,847, artinya keputusan minat mahasiswa memilih berkarir di bidang perpajakan sebagai variabel dependen mampu dijelaskan oleh variabel independen yaitu persepsi, motivasi, minat, dan pengetahuan perpajakan sebesar $84,7 \%$, sedangkan sisanya sebesar 15,3\% dijelaskan oleh faktor lain diluar model peneltian ini.

\section{Uji Statistik t}

Berdasarkan hasil uji t tabel 10 menyatakan bahwa variabel persepsi menunjukan nilai koefesien beta sebesar 0,183 dengan nilai signifikansi sebesar $0,005<0,05$. Dengan demikian dapat disimpulkan bahwa persepsi berpengaruh positif terhadap keputusan mahasiswa memilih berkarir dibidang perpajakan, sehingga hipotesis pertama (H1), diterima.

Variabel motivasi menunjukan nilai koefesien beta sebesar 0,236 dengan nilai signifikansi sebesar $0,001<0,05$. Dengan demikian dapat disimpulkan bahwa motivasi berpengaruh positif terhadap keputusan mahasiswa memilih berkarir dibidang perpajakan, sehingga hipotesis pertama (H2), diterima.

Variabel minat menunjukan nilai koefesien beta sebesar 0,130 dengan nilai signifikansi sebesar $0,016<0,05$. Dengan demikian dapat disimpulkan bahwa minat berpengaruh positif terhadap keputusan mahasiswa memilih berkarir dibidang perpajakan, sehingga hipotesis pertama $(\mathrm{H} 3)$, diterima.

Variabel pengetahuan perpajakan menunjukan nilai koefesien beta sebesar 0,474 dengan nilai signifikansi sebesar $0,000<0,05$. Dengan demikian dapat disimpulkan bahwa minat berpengaruh positif terhadap keputusan mahasiswa memilih berkarir dibidang perpajakan, sehingga hipotesis pertama $(\mathrm{H} 4)$, diterima.

\section{PEMBAHASAN}

\section{Pengaruh Persepsi Terhadap Keputusan Pemilihan Berkarir Di Bidang Perpajakan}

Hipotesis pertama menyatakan bahwa persepsi berpengaruh positif terhadap keputusan mahasiswa memilih berkarir di bidang perpajakan. Artinya, apabila mahasiswa memiliki pemikiran atau persepsi tentang karir di bidang perpajakan maka mahasiswa tersebut akan berperilaku sesuai dengan apa yang diharapkan. Berdasarkan persepsi yang baik tentunya akan memunculkan tingginya minat mahasiswa berkarir dibidang perpajakan. Hasil penelitian ini didukung oleh peneliti terdahulu yang dilakukan oleh Mahayani, dkk (2017); Rachmawati, dkk (2017); Pradnyani, dkk (2018); Yasa, dkk (2019); Anggraeni , dkk (2020).

\section{Pengaruh Motivasi Terhadap Keputusan Pemilihan Berkarir Di Bidang Perpajakan}

Hipotesis kedua menyatakan bahwa motivasi berpengaruh positif terhadap keputusan mahasiswa memilih berkarir di bidang perpajakan. Artinya, mahasiswa yang menguasai ilmu perpajakan memiliki daya tarik untuk terjun berkarir dibidang perpajakan. Seseorang yang berkarir di bidang perpajakan biasanya dianggap sebagai pekerjaan yang prestis, apresiasi terhadap prestasi yang tinggi, sebagai ajang bergaul dan bekerja sama dengan orang lain. Hal ini juga berpengaruh kepada orang lain, sehingga apabila motivasi sosial mahasiswa itu baik dengan karir dibidang perpajakan maka akan berpengaruh terhadap minat mahasiswa untuk berkarir di bidang perpajakan juga tinggi. Hasil penelitian ini didukung oleh peneliti terdahulu yang dilakukan oleh Mahayani, dkk (2017); Rachmawati, dkk (2017); Meilani (2020); Anggraeni, dkk (2020); Prihatin, dkk (2020); Nareswari, dkk (2021) 
Owner: Riset \& Jurnal Akuntansi

e-ISSN : 2548-9224 | p-ISSN : 2548-7507

Volume 6 Nomor 1, Januari 2022

DOI : https://doi.org/10.33395/owner.v6i1.622

\section{Pengaruh Minat Terhadap Keputusan Pemilihan Berkarir Di Bidang Perpajakan}

Hipotesis ketiga menyatakan bahwa minat berpengaruh terhadap keputusan mahasiswa memilih berkarir di bidang perpajakan. Artinya, mahasiswa memiliki minat atau keinginan tertentu maka secara tidak langsung akan mempengaruhi usaha yang akan dilakukan untuk mencapai tujuannya tersebut untuk berkarir di bidang perpajakan. Mahasiswa akan memilih karir di bidang perpajakan ketika mahasiswa tersebut berminat untuk berkarir dibidang perpajakan. Hasil penelitian ini didukung oleh peneliti terdahulu yang dilakukan oleh Mahayani, dkk (2017).

\section{Pengaruh Pengetahuan Perpajakan Terhadap Keputusan Pemilihan Berkarir Di Bidang Perpajakan}

Hipotesis keempat menyatakan bahwa pengetahuan perpajakan berpengaruh terhadap keputusan mahasiswa memilih berkarir di bidang perpajakan. Artinya, apabila seseorang memiliki kemauan untuk belajar melalui pendidikan formal maupun non formal mengenai tata cara dan ketentuan perpajakan maka seseorang tersebut akan meningkatkan pengetahuannya mengenai perpajakan. Melalui tingkatan pendidikan yang dilalui oleh mahasiswa maka ilmu yang didapat akan semakin meningkat pula. Pengetahuan yang dimaksud adalah pengetahuan mengenai sistem perpajakan, caracara menghitung pajak. Dengan demikian, mendorong mahasiswa memiliki suatu gambaran mengenai hal-hal yang akan ia kerjakan, apabila bekerja dibidang perpajakan. Hasil penelitian ini sejalan oleh penelitian Mahayani, dkk (2017); Meilani (2020); Nareswari, dkk (2021).

\section{KESIMPULAN}

Berdasarkan hasil penelitian dan atas dasar hasil pengujian hipotesis maka dapat diambil kesimpulan bahwa persepsi berpengaruh positif terhadap keputusan pemilihan berkarir di bidang perpajakan, hal ini menunjukkan bahwa mahasiswa yang berkarir di bidang perpajakan memiliki persepsi yang baik mengenai perpajakan. Motivasi berpengaruh positif terhadap keputusan pemilihan berkarir di bidang perpajakan, hal ini menujukan bahwa mahasiswa yang berkarir di bidang perpajakan memiliki motivasi yang baik mengenai perpajakan. Minat berengaruh positif terhadap keputusan pemilihan berkarir dibidang perpajakan, hal ini menunjukan bahwa mahasiswa yang berkarir di bidang perpajakan memiliki minat yang tinggi mengenai perpajakan. Pengetahuan perpajakan berpengaruh positif terhadap keputusan pemilihan berkarir di bidang perpajakan, hal ini menunjukan bahwa mahasiswa yang berkarir di bidang perpajakan memiliki pengetahuan perpajakan yang baik mengenai perpajakan.

\section{REFERENSI}

Amin, K. (2016). Asuhan Keprawatan Berdasarkan Diagnosa Medis NANDA NICNOC. Mediactio Publishing.

Anggraeni, M. A., Maslichah, \& Sudaryanti, D. (2020). PENGARUH PERSEPSI DAN MOTIVASI TERHADAP MINAT MAHASISWA JURUSAN AKUNTANSI BERKARIR DI BIDANG PERPAJAKAN (Studi Empiris pada Mahasiswa Akuntansi Universitas Islam Malang) . E$J R A, 1-12$.

Ghozali , I. (2005). Aplikasi Analisis Multivariate dengan SPSS. Semarang: Badan Penerbit UNDIP.

Ghozali , I. (2013). Aplikasi Analisis Multivariate dengan Program SPSS 21 Update PLS Regresi. Semarang : Badan Penerbit Universitas Diponegoro.

Ghozali , I. (2018). Aplikasi Analisis Multivariate dengan Program IBM SPSS 25 . Semarang: Badan Penerbit Universitas Diponegoro.

Ghozali, I. (2006). Aplikasi Analisis Multivariate dengan Program SPSS. UNDIP Semarang : Badan Penerbit Universitas Diponegoro.

Ghozali, I. (2013). Aplikasi Analisis Multivariate dengan Program SPSS (Edisi ke 4). Semarang: Badan Penerbit Universitas Diponegoro.

Ghozali, I. (2016). Aplikasi Analisis Multivariete dengan Program IBM SPSS 23 (Edisi 8) cetakan ke VIII. Semarang: Badan Penerbit Universitas Diponegoro. 
Hawani, I., \& Rahmayani, A. (2016). Pengaruh Mahasiswa Akuntansi Tentang Pajak san Audit Terhadap Minat Berkarir Dibidang Perpajakan dan Audit. Media Akuntansi Perpajakan, 6274.

Mahayani, N. M., Sulindawati, N. L., \& Herawati, N. T. (2017). PENGARUH PERSEPSI, MOTIVASI, MINAT, DAN PENGETAHUAN MAHASISWA AKUNTANSI PROGRAM S1 TENTANG PAJAK TERHADAP PILIHAN BERKARIR DIBIDANG PERPAJAKAN . e-Journal Nama Jurnal Universitas Pendidikan Ganesha , 1-11.

Meilani, N. (2020). PENGARUH ETIKA PROFESI PERPAJAKAN, PENGETAHUAN PERPAJAKAN, BREVET PAJAK, DAN MOTIVASI TERHADAP MINAT BERKARIR DI BIDANG PERPAJAKAN. Prisma (Platfrom Riset Mahasiswa Akuntansi, 1-14.

Nareswari, M., Junaid, A., \& Shaleh, M. (2021). Pengaruh Motivasi dan Pengetahuan Perpajakan Terhadap Minat Mahasiswa Berkarir di Bidang Perpajakan. CESJ : Center Of Economics Students Journal , 1-8.

Prasetyo, d. (2016). Pengaruh Motivasi dan Persepsi Terhadap Pilihan Profesi dengan Minat Mengikuti Pelatihan Brevet Pajak sebagai Varibael Intervening. Simposium Nasional Akuntansi XIX, Lampung.

Prihatini, P. A., \& Rachmawati, N. A. (2020). PENGARUH MOTIVASI, EFEKTIVITAS PEMBELAJARAN MATA KULIAH PERPAJAKAN DAN KESEMPATAN KERJA DI BIDANG PERPAJAKAN TERHADAP MINAT MAHASISWA AKUNTANSI DALAM BERKARIR DI BIDANG PERPAJAKAN . PROCEDING NCAA, 1-21.

Rachmawati, L., \& Indra Pahala. (2018). PENGARUH PERSEPSI DAN MOTIVASI TERHADAP MINAT BERKARIR MAHASISWA DI BIDANG PERPAJAKAN JURUSAN AKUNTANSI FAKULTAS EKONOMI PADA UNIVERSITAS NEGERI JAKARTA . FAKULTAS EKONOMI UNIVERSITAS NEGERI JAKARTA REPOSITORY, 1-15.

Samsuri, Binti, A. S., and Hasan, T. R., \& Binti , S. (2016). Perception Of Undergraudate Accounting Students to wards Professional Accounting Career. International Journal of Academic Research InAccounting, Finance and Management Sciences, 78-88.

Setya, D. (2017). Pengaruh Persepsi dan Motivasi Terhadap Minat Mahasiswa Jurusan Akuntansi Syariah Untuk Berkarir Dibidang Pajak (Studi empirs Pada Mahasiswa AkuntansI Syariah). 123 doc, $1-120$.

Supramono, \& Utami, I. (2004). Desain Proposal Penelitian Akuntansi \& Keuangan. Yogyakarta.

Trisnawati, K, M., \& Khoiru, R. M. (2015). Pengaruh Persepsi dan Motivasi Terhadap Minat Mahasiswa Jurusan Akuntansi Fakultas Ekonomika dan Bisnis Universitas Brawijaya Berkarir Di Bidang Perpajakan. Jurnal Ilmiah Mahasiswa FEB UB, 1-15.

Y, R. (2015). Pengaruh Model Pembelajaran Learning Cycle 5e terhadap Kemampuan Pemecahan Masalah Matematis Siswa SMP. Skripsi UNPAS Bandung .

Yasa, I. N., Pradnyani, I. A., \& Atmadja, A. T. (2019). PERAN LINGKUNGAN, PERTIMBANGAN PASAR KERJA DAN PERSEPSI MAHASISWA PENGARUHNYA TERHADAP KEPUTUSAN MAHASISWA BERKARIR DI BIDANG PERPAJAKAN I . Jurnal KRISNA: Kumpulan Riset Akuntansi, 1-9. 